Article

\title{
Apocynin-Tandospirone Derivatives Suppress Methamphetamine-Induced Hyperlocomotion in Rats with Neonatal Exposure to Dizocilpine
}

\author{
Takashi Uehara ${ }^{1, *}$, Masayoshi Kurachi ${ }^{2,+}$, Takashi Kondo ${ }^{3}$, Hitoshi Abe ${ }^{4} \mathbb{D}$, Hiroko Itoh ${ }^{2}$, Tomiki Sumiyoshi ${ }^{5}$ \\ and Michio Suzuki ${ }^{2}$
}

check for

updates

Citation: Uehara, T.; Kurachi, M.;

Kondo, T.; Abe, H.; Itoh, H.;

Sumiyoshi, T.; Suzuki, M.

Apocynin-Tandospirone Derivatives

Suppress Methamphetamine-Induced

Hyperlocomotion in Rats with

Neonatal Exposure to Dizocilpine. J.

Pers. Med. 2022, 12, 366.

https://doi.org/10.3390/

jpm12030366

Academic Editor: Toshiaki Onitsuka

Received: 26 January 2022

Accepted: 25 February 2022

Published: 27 February 2022

Publisher's Note: MDPI stays neutral with regard to jurisdictional claims in published maps and institutional affiliations.

Copyright: (c) 2022 by the authors. Licensee MDPI, Basel, Switzerland. This article is an open access article distributed under the terms and conditions of the Creative Commons Attribution (CC BY) license (https:/ / creativecommons.org/licenses/by/ $4.0 /)$.
1 Department of Neuropsychiatry, Kanazawa Medical University, Uchinada 920-0293, Japan

2 Department of Neuropsychiatry, Graduate School of Medicine and Pharmaceutical Sciences, University of Toyama, Toyama 930-0194, Japan; uehara_takasayu@yahoo.co.jp (M.K.); mugen@med.u-toyama.ac.jp (H.I.); suzukim@med.u-toyama.ac.jp (M.S.)

3 Center for Low-Temperature Plasma Sciences, Nagoya University, Nagoya 464-8603, Japan; tasakondo@khc.biglobe.ne.jp

4 Department of Applied Chemistry, Faculty of Engineering, University of Toyama, Toyama 930-8555, Japan; abeh@eng.u-toyama.ac.jp

5 Department of Preventive Intervention for Psychiatric Disorders, National Institute of Mental Health, National Center of Neurology and Psychiatry, Tokyo 187-8551, Japan; sumiyot@ncnp.go.jp

* Correspondence: uehara@kanazawa-med.ac.jp; Tel.: +81-76-286-2211 (ext. 3437); Fax: +81-76-286-3341

† Deceased 13 November 2019.

\begin{abstract}
Accumulating evidence implicates oxidative stress as a potential pathophysiological mechanism of schizophrenia. Accordingly, we synthesized new chemicals using apocynin and tandospirone as lead compounds (A-2, A-3 and A-4). These novel compounds decreased reactive oxygen species (ROS) concentrations in vitro and reversed decreases in glutathione levels in the medial prefrontal cortex of rats transiently exposed to MK-801, an N-methyl-D-aspartate receptor antagonist, in the neonatal period. To determine whether A-2, A-3 and A-4 show behavioral effects associated with antipsychotic properties, the effects of these compounds on methamphetamine (MAP)-induced locomotor and vertical activity were examined in the model rats. A-2 and A-3, administered for 14 days around the puberty period, ameliorated MAP-induced hyperlocomotion in MK-801-treated rats in the post-puberty period, while A-4 suppressed MAP-induced vertical activity. These findings indicate that apocynin-tandospirone derivatives present anti-dopaminergic effects and may alleviate psychotic symptoms of schizophrenia.
\end{abstract}

Keywords: apocynin; tandospirone; antioxidant; MK-801; locomotion; animal model; schizophrenia

\section{Introduction}

Redox dysregulation, $\mathrm{N}$-methyl-D-aspartate (NMDA) receptor hypofunction and neuroinflammation may represent an aspect of the pathophysiology of schizophrenia [1]. For example, accumulating evidence has indicated increased oxidative stress in patients with schizophrenia and its prodromal phase [2,3]. Animal model studies have reported that NMDA receptor hypofunction in early life stages induces oxidative stress that causes reduction in the number of parvalbumin (PV)-positive $\gamma$-aminobutyric acid (GABA) interneurons in the prefrontal cortex (PFC) [4].

Decreased levels of redox substrates, especially glutathione (GSH), have been observed in cerebrospinal fluid (CSF), brain tissues, and whole blood of patients with schizophrenia [5]. Specifically, GSH levels are lower in the PFC of these patients, as measured by in vitro assay of postmortem brain tissues or proton magnetic resonance spectroscopy-based imaging [6,7]. GSH levels are also decreased in erythrocytes and plasma of patients with first-episode psychosis $[8,9]$. Moreover, erythrocyte GSH levels in individuals at ultra-high risk state 
have been reported to predict transition to psychosis [10]. These findings indicate that impairments in the GSH system may occur early in the illness trajectory and continue into the chronic phase.

A randomized controlled trial [11] found that N-acetylcysteine (NAC), an antioxidant and precursor of GSH, alleviated positive symptoms in patients with early phase schizophrenia, which was accompanied by an increase in GSH levels in the medial PFC. On the other hand, treatment with NAC prevented amphetamine (AMPH)-induced hyperlocomotion in a mice model of schizophrenia $[12,13]$ that were exposed to social isolation rearing [14]. These findings suggest that antioxidants may ameliorate and/or prevent the hypersensitivity, reflecting increased dopamine (DA) transmissions in the limbic areas, through correcting GSH deficiency.

We synthesized new chemicals using apocynin and tandospirone as lead compounds [15], and have reported the ability of these chemicals to decrease reactive oxygen species (ROS) induced by X-irradiation in human lymphoma U937 cells [15]. Moreover, treatment with these compounds for 14 days around puberty ameliorated the decrease in GSH (mainly reduced GSH) levels and the reduction in PV-positive neurons in the medial prefrontal cortex (mPFC) of rats transiently exposed to MK-801, a highly potent and selective noncompetitive NMDA receptor antagonist, in the neonatal period [15]. These findings indicate antioxidant properties of the apocynin-tandospirone derivatives that normalize the GSH system.

The aim of this study was to determine whether apocynin-tandospirone derivatives elicit antipsychotic properties using an animal model of schizophrenia. For this purpose, we administered these compounds repeatedly to rats transiently exposed to MK-801 in the neonatal period, and examined methamphetamine (MAP)-induced locomotor and vertical activity. As reference compounds, clozapine (CLZ) and olanzapine (OLA) were selected, because these antipsychotic drugs are most commonly used to treat positive and negative symptoms of schizophrenia [16], and have been shown to protect against oxidative stress [17-19].

\section{Materials and Methods}

\subsection{Animals and Neonatal MK-801 Treatment}

Animal models were prepared based on previous reports [20-23]. Female Wistar rats obtained at 14 days of pregnancy (Japan SLC, Shizuoka, Japan) were individually housed at $24 \pm 2{ }^{\circ} \mathrm{C}$ under a $12 \mathrm{~h}$ light-dark cycle (7:00-19:00) with free access to food and water. On PD 7, male pups (7-15 g) were randomly divided into two groups; they received MK801 (dizocilpine, $0.20 \mathrm{mg} / \mathrm{kg}$, s.c.; Sigma-Aldrich, St. Louis, MO, USA; MK-801 neonatal treatment group) or an equal volume of saline (control; saline group) once daily for 4 days. Pups in each group came from at least 2 independent litters and received injections between 8:00 and 10:00. After weaning at PD 21, pups were group-housed by treatment (4-6 animals per cage with free access to food and water). The procedures complied with the National Institutes of Health guide for the care and use of Laboratory animals. All experiments were reviewed and approved by the Committee of Animal Research, University of Toyama.

\subsection{Drug Administration}

CLZ and OLA were purchased from Wako Pure Chemical Industries Co. (Osaka, Japan). npApocynin-tandospirone derivatives (A-2, A-3, A-4; Figure 1) were synthesized in our laboratory [15]. They were dissolved in saline and were administered s.c. at $2.5 \mathrm{mg} / \mathrm{kg}$. CLZ or OLA were administered at $5.0 \mathrm{mg} / \mathrm{kg}$ (s.c.) and $0.2 \mathrm{mg} / \mathrm{kg}$ (s.c.), respectively. An equal volume of saline was used as a vehicle. Animals were assigned to one of the following 12 groups: saline-saline group $(n=12)$, MK801-saline group $(n=12)$, saline-A2 group $(n=12)$, MK801-A2 group $(n=13)$, saline-A3 group $(n=12)$, MK801-A3 group $(n=12)$, saline-A4 group $(n=13)$, MK801-A4 group $(n=13)$, saline-CLZ group $(n=12)$, MK801-CLZ group $(n=12)$, saline-OLA group $(n=12)$, and MK801-OLA group $(n=12)$. All drugs or saline were administered once daily (8:00-10:00) for 14 days (PD 43-56). 


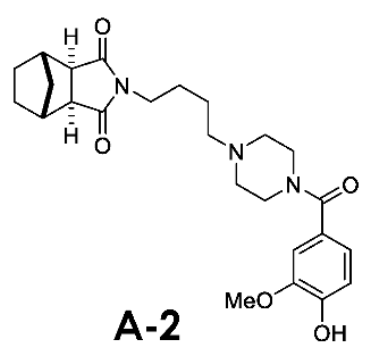<smiles>COc1cc(C(C)=O)ccc1O</smiles>

Apocynin

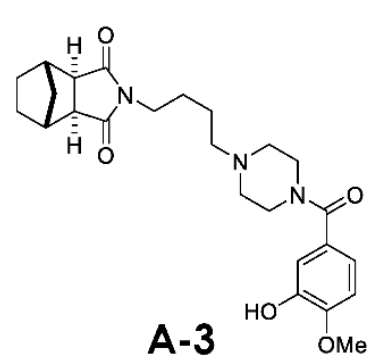<smiles>O=C(c1ccc(O)c(O)c1)N1CCN(CCCCN2C(=O)C3C4CCC(C4)C3C2=O)CC1</smiles><smiles>O=C1C2C3CCC(C3)C2C(=O)N1CCCCN1CCN(c2ncccn2)CC1</smiles>

Tandospirone

Figure 1. Chemical structures of three apocynin-tandospirone derivatives (A-2, A-3, and A-4) and their lead chemicals (apocynin and tandospirone).

\subsection{Locomotor Activity Testing}

Locomotor activity was tested on PD 57 ( $24 \mathrm{~h}$ after the last drug administration). Locomotion was measured in an ambulation observation chamber (blackened vinyl chloride cages, $40 \mathrm{~cm} \times 40 \mathrm{~cm} \times 40 \mathrm{~cm}$; AMB-3001, Ohara \& Co., Ltd., Tokyo, Japan) equipped with $6 \times 6$ photoelectric light sources spaced at $7 \mathrm{~cm}$ intervals and $2.5 \mathrm{~cm}$ (for horizontal locomotion) above the floor (AMB-2020, Ohara \& Co., Ltd.) [20,22,24]. Vertical activity was measured using photoelectric light sources spaced $19 \mathrm{~cm}$ above the floor [22]. Rats were brought to the testing room in their home cages and were immediately placed in the test chamber. Spontaneous activity was measured for $15 \mathrm{~min}$. Then, each rat was administered (s.c.) $1.0 \mathrm{mg} / \mathrm{kg}$ MAP (3.0 mg/mL; Dainippon Sumitomo Pharmaceuticals, Tokyo, Japan) $30 \mathrm{~min}$ after placed in the test chamber, and MAP-induced activity was recorded for $90 \mathrm{~min}$. Interruptions of light beams were registered as activity counts and were summarized every 5 min by the Logger Interface control system (IF-10-LOG, Ohara \& Co., Ltd.) (Figure 2).

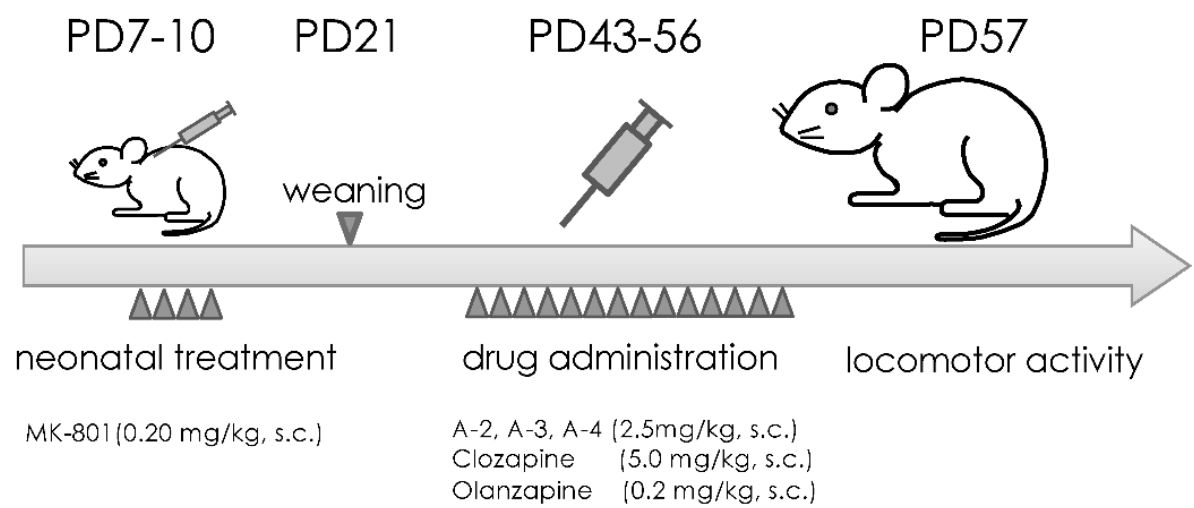

Figure 2. Schematic representation of experiments for neonatal treatment (MK-801), drug administration (A-2, A-3, A-4, clozapine and olanzapine) and locomotor activity testing. PD, postnatal days.

\subsection{Presentation of the Results and Statistics}

Data were analyzed by SPSS software (version 19.0 J for Mac, SPSS Japan Inc., Tokyo, Japan). For comparison of spontaneous locomotor activity and vertical activity, two-way ANOVA was performed with neonatal treatment status (treatment: MK-801 and saline) and drug administration (drug, A-2, A-3, A-4, CLZ, OLA and saline). For comparison of MAP- 
induced locomotor activity and vertical activity, activity counts were obtained for every 15 min. Repeated measures ANOVA with treatment status (treatment: MK-801 and saline) and drug administration (drug: A-2, A-3, A-4, CLZ, OLA and saline) as between-subject factor, and time as within-subject factor was treated as repeated-measures variable. When appropriate, repeated-measures ANOVA were performed for each drug administration (A-2, A-3, A-4, CLZ, OLA vs. saline) separately, because our a priori hypothesis predicted the effect of apocynin-tandospirone derivatives on hyperlocomotion induced by neonatal MK801 treatment. Moreover, this was followed by one-way ANOVA and post hoc Bonferroni tests were used to evaluate between-group differences at each time. A probability (p) of less than 0.05 was considered to be significant.

\section{Results}

\subsection{Spontaneous Locomotion}

There was no significant treatment $\times$ drug interaction or main effect of neonatal treatment status or drug administration (Figure 3).

A

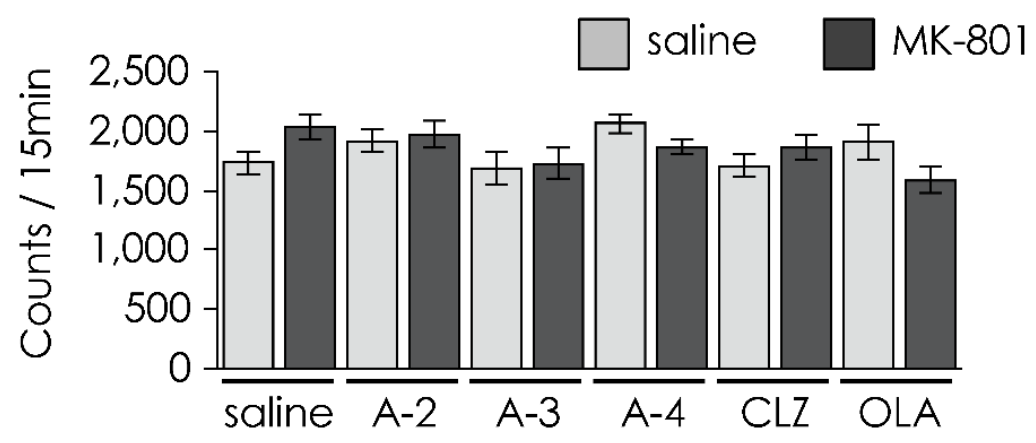

B

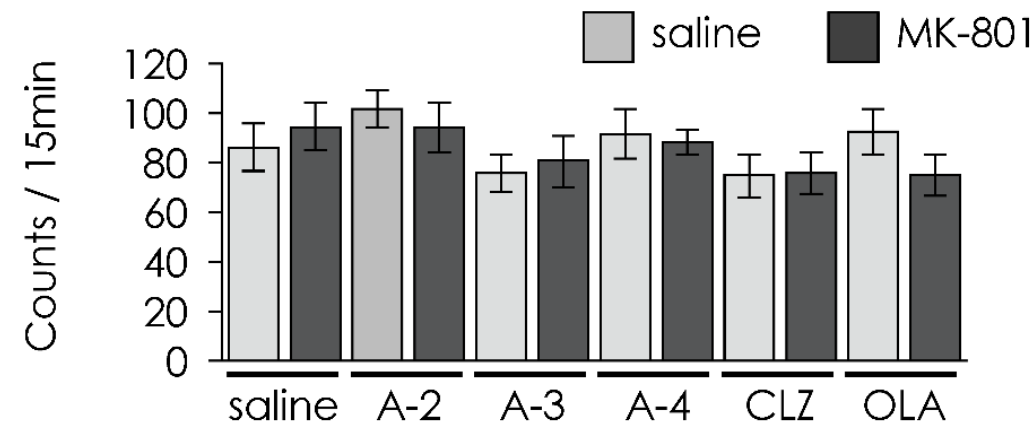

Figure 3. Effect of 14-day (PD 43-56) treatment with apocynin-tandospirone derivatives and antipsychotics on spontaneous (A) locomotor activity and (B) vertical activity (for $15 \mathrm{~min}$ after placed in the test chamber) on PD 57. Saline-saline group $(n=12)$, MK801-saline group $(n=12)$, saline-A2 group $(n=12)$, MK801-A2 group $(n=13)$, saline-A3 group $(n=12)$, MK801-A3 group $(n=12)$, saline-A4 group ( $n=13)$, MK801-A4 group $(n=13)$, saline-CLZ group $(n=12)$, MK801-CLZ group $(n=12)$, saline-OLA group $(n=12)$, and MK801-OLA group $(n=12)$. Values are expressed as means \pm SEM.

\subsection{MAP-Induced Locomotion}

There were drug $\times$ time interactions $(\mathrm{F}(30,810)=2.26, p<0.001)$ and main effects of drug $(\mathrm{F}(5135)=3.03, p=0.013)$. These results demonstrated that there were different effects on MAP-induced hyperlocomotion between drug administration. Next, repeated- measures ANOVA were performed for each drug administration (A-2, A-3, 
A-4, CLZ, OLA vs. saline) separately. Administration of A-2, A-3 or OLA ameliorated increased MAP-induced locomotor activity in MK-801 treated animals (Figure 4A,B,E). There were significant treatment $\times$ drug $\times$ time interactions $(F(6270)=2.68, p=0.015)$ and treatment $\times$ drug interactions $(\mathrm{F}(1,45)=6.64, p=0.013)$ with A-2. Significant treatment $\times$ drug interaction with A-3 and with OLA $(\mathbf{A}-3 ; \mathrm{F}(1,44)=4.64, p=0.037, \operatorname{OLA} ; \mathrm{F}(1,44)=5.54$, $p=0.023$, respectively).
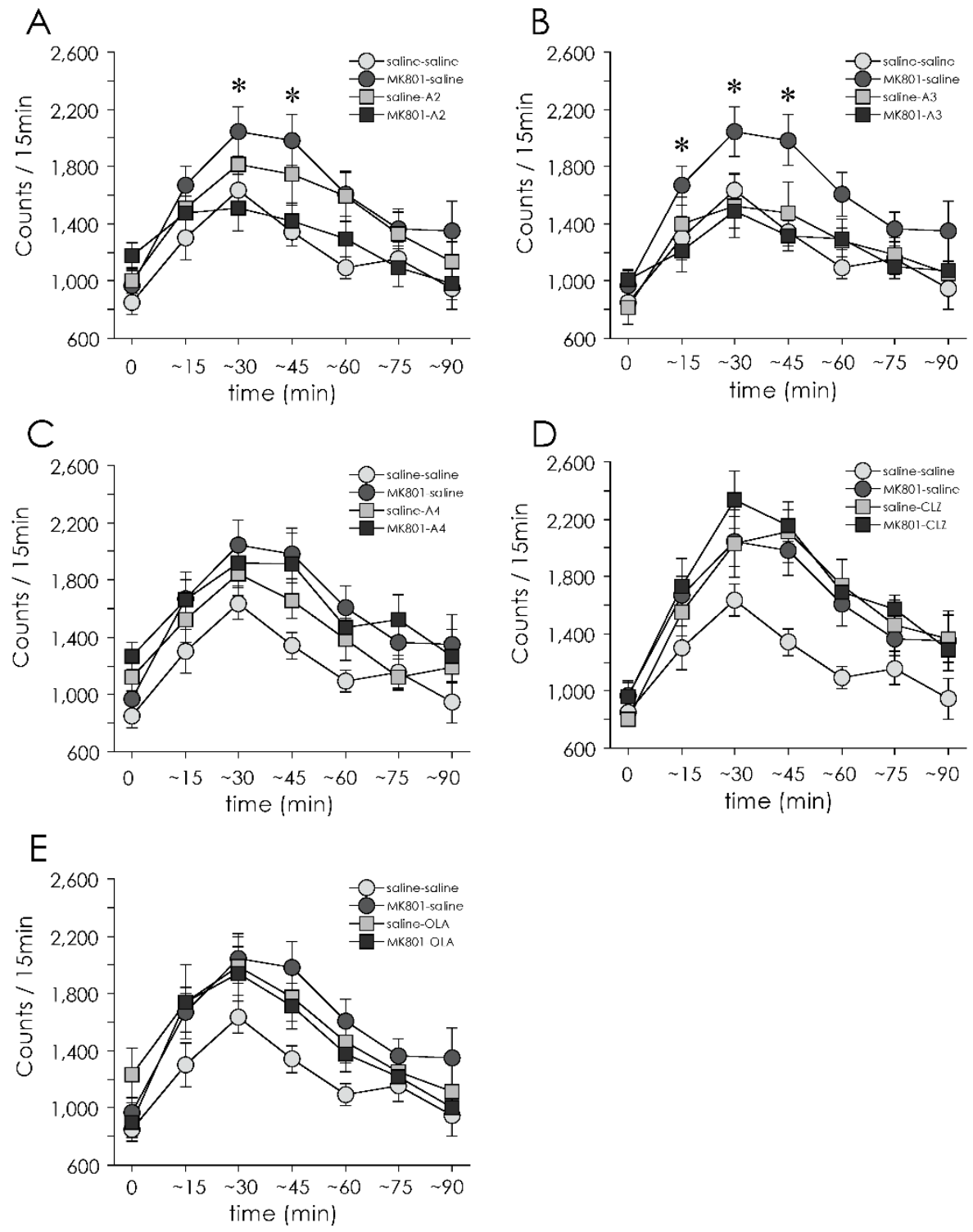

Figure 4. Effect of 14-day (PD 43-56) treatment with apocynin-tandospirone derivatives and antipsychotics on MAP-induced locomotor activity (for $90 \mathrm{~min}$ ) on PD 57. Data with A-2 (A), A-3 (B), A-4 (C), CLZ (D) and OLA (E) are shown. Saline-saline group $(n=12)$, MK801-saline group $(n=12)$, saline-A2 group $(n=12)$, MK801-A2 group $(n=13)$, saline-A3 group $(n=12)$, MK801-A3 group $(n=12)$, saline-A4 group $(n=13)$, MK801-A4 group $(n=13)$, saline-CLZ group $(n=12)$, MK801-CLZ group $(n=12)$, saline-OLA group $(n=12)$, and MK801-OLA group $(n=12)$. Values are expressed as means \pm SEM. ${ }^{*} p<0.05$ compared MK-801-A-2 or A-3 with MK-801-saline group.

Next, we sought to determine if the effect of A-2, A-3 and OLA on MAP-induced hyperlocomotion in MK-801 treated rats would be affected by time. The augmentation of an increase in MAP-induced locomotor activity in MK-801 treated animals was significantly suppressed from 16 to 45 min with A-2 and 1 to 45 min with A-3 after MAP injection 
(Ps $<0.05$, one-way ANOVA followed by Bonferroni test), whereas OLA did not decrease MAP-induced hyperlocomotion at each time.

A-4 had no effect on MAP-induced locomotor activity in the rats treated with neonatal MK-801 (Figure 4C). On the other hand, there were significant drug $\times$ time interaction $(\mathrm{F}(6264)=2.17, p=0.047)$ and significant main effects of treatment $(\mathrm{F}(1,44)=5.65, p=0.022)$ and drug administration $(\mathrm{F}(1,47)=6.17, p=0.017)$ with CLZ (Figure 4D). This result indicated that CLZ increased locomotor activity by itself.

\subsection{MAP-Induced Vertical Activity}

Repeated measures ANOVA demonstrated a significant drug $\times$ time interaction $(\mathrm{F}(30,810)=1.75, p=0.008)$. This result showed that there were different effects on MAPinduced vertical activity between drug administration. Then, repeated-measures ANOVA was conducted to examine drug administration effects of each drug (A-2, A-3, A-4, CLZ, OLA vs. saline) on MAP-induced vertical activity separately. There was treatment $\times$ drug interaction $(\mathrm{F}(1,46)=5.04, p=0.03)$ with A-4 (Figure $5 \mathrm{C}$ ). Administration of A-2, A-3 or OLA did not affect MAP-induced vertical activity (Figure 5A,B,E). CLZ intensified MAPinduced vertical activity (drug administration $\times$ time interaction, $\mathrm{F}(6264)=2.58, p=0.019$ ) (Figure 5D).

A

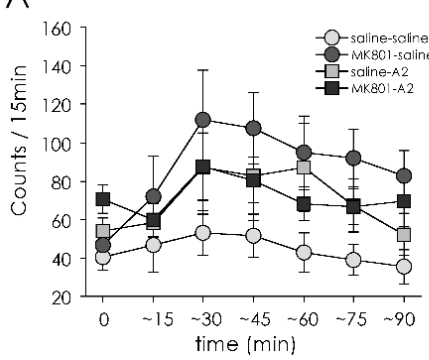

C

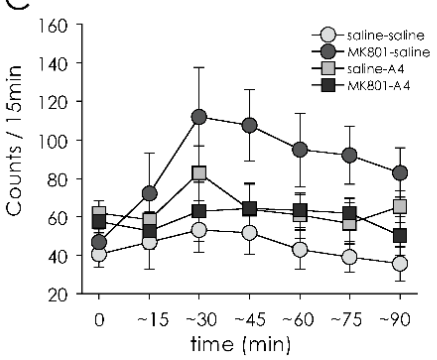

E

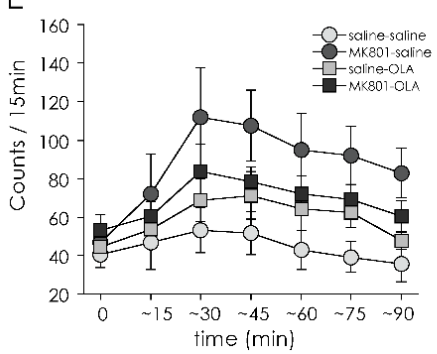

B

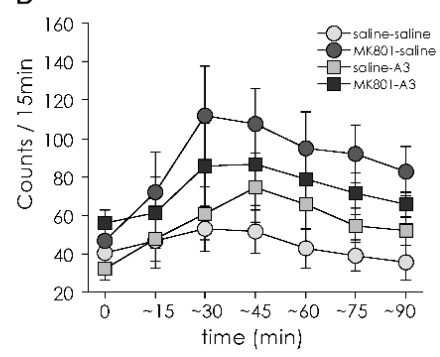

D

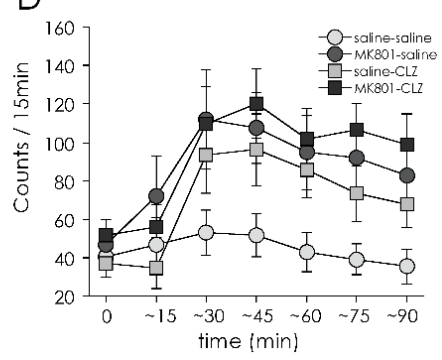

Figure 5. Effect of 14-day (PD 43-56) treatment with apocynin-tandospirone derivatives and antipsychotics on MAP-induced vertical activity (for 90 min) on PD 57. Data with A-2 (A), A-3 (B), A-4 (C), CLZ (D) and OLA (E) are shown. Saline-saline group $(n=12)$, MK801-saline group $(n=12)$, saline-A2 group ( $n=12)$, MK801-A2 group $(n=13)$, saline-A3 group $(n=12)$, MK801-A3 group ( $n=12)$, saline-A4 group $(n=13)$, MK801-A4 group $(n=13)$, saline-CLZ group $(n=12)$, MK801-CLZ group $(n=12)$, saline-OLA group $(n=12)$, and MK801-OLA group $(n=12)$. Values are expressed as means \pm SEM. 


\section{Discussion}

This study demonstrated that A-2, A-3 and OLA, but not A-4, suppressed MAPinduced hyperlocomotion in rats exposed to neonatal MK-801. Inhibition of hyperlocomotion by A-2 and A-3 occurred in the early phase (within $45 \mathrm{~min}$ ) after MAP administration. On the other hand, only A-4 ameliorated increased MAP-induced vertical activity. By contrast, spontaneous locomotor and vertical activities were not affected by any of the test drugs, suggesting that A-2 and A-3 show antidopaminergic properties in the model rats (Table 1).

Table 1. Effects of apocynin-tandospirone derivatives and antipsychotic drugs on locomotor and vertical activity.

\begin{tabular}{ccccc}
\hline & \multicolumn{2}{c}{ Spontaneous } & \multicolumn{2}{c}{ MAP-Induced } \\
\cline { 2 - 5 } & Locomotor Activity & Vertical Activity & Locomotor Activity & Vertical Activity \\
\hline A-2 & - & - & - & - \\
A-3 & - & - & - & - \\
A-4 & - & - & - & - \\
CLZ & - & - & $\downarrow$ & - \\
OLA & - & - & $\downarrow$ \\
\hline
\end{tabular}

Arrow demonstrates suppressed effect of drug on MAP-induced hyperactivity. Minus sign "_" shows no change compared with spontaneous or methamphetamine-induced activity. MAP, methamphetamine; CLZ, clozapine; OLA, olanzapine.

\subsection{Effects of New Chemicals and Atypical Antipsychotics on MAP-Induced Hyperactivity}

The results of this study are consistent with the observations that NMDA antagonists, such as phencyclidine (PCP) and MK-801, during the early developmental stage causes long-term alterations in behavioral activity in rodents [20,22,25,26]. Since MAP-induced hyperlocomotion is closely related to enhanced dopamine release in the nucleus accumbens (NAC) [27], blockade of NMDA receptors in the neonatal stage may lead to exaggerated dopamine transmissions in this brain region.

A-2 and A-3 significantly inhibited MAP-induced hyperlocomotion in MK-801-treated rats, especially immediately after MAP administration, indicating that repeated treatment with A-2 or A-3 attenuates MAP-induced hyperdopaminergic states. These findings are in line with the observations which indicates repeated treatment with apocynin, a lead compound of A-2 and A-3, attenuates the hyperlocomotion induced by MAP [28]. Moreover, similar behavioral changes were also observed at post-puberty, but not pre-puberty $[20,22]$, indicating blockade of NMDA receptors between PD 7 and 10 causes delayed emergence of hyperdopaminergic states. In fact, this is reminiscent of the manifestation of positive symptoms of schizophrenia at the time of sexual maturation [29]. The ability of A-2 or A-3 to attenuate the behavioral abnormalities suggests that these compounds would potentially prevent the development of psychosis in subjects with vulnerable traits. On the other hand, A-4 did not suppress MAP-induced hyperlocomotion in model rats, while it attenuated MAP-induced vertical activity. As this type of exploratory behaviors (e.g., rearing) are governed by mesolimbic and mesocortical dopaminergic transmissions [30-32], A-4 may also elicit anti-dopaminergic effects in these dopaminergic pathways.

In this study, OLA suppressed MAP-induced hyperlocomotion in MK-801 treated rats, whereas CLZ intensified MAP-induced locomotor and vertical activities. These observations are in line with the ability of chronic treatment with OLA to alleviate AMPHinduced hyperlocomotion in sensitized mice [33]. By contrast, repeated administration of CLZ does not attenuate MAP-induced hyperlocomotion [34,35] or reverse AMPH-induced hyperlocomotion [36].

The ability of acute CLZ or OLA administration to inhibit AMPH-induced hyperlocomotion is considered to be mediated by the antagonistic action on dopamine D2 receptors [34]. However, the inhibitory effect of CLZ, but not OLA is gradually weakened by repeated administration [34]. Acute administration of AMPH increases free radical $\left(\mathrm{H}_{2} \mathrm{O}_{2}\right)$ formation 
and decreases GSH levels in the striatum of rats [37]. Five-day treatment with AMPH induces extensive oxidative stress and long-lasting glial reactivity in the PFC [38]. Moreover, long-term use of AMPH or MAP injures both dopaminergic and serotonergic neurons, which is mediated, in part, by oxidative stress [39]. Therefore, reversal of MAP- or AMPH- induced hyperlocomotion in sensitized animals by chronic OLA treatment may be associated with protection against oxidative stress. On the other hand, chronic treatment with CLZ have been reported to reduce GSH levels in the PFC of naïve- [40] or MK-801-treated rats [15]. Thus, in the model rat studied here, CLZ augmented dopamine transmissions, possibly by attenuating activities of the GSH antioxidative system.

It is noteworthy that the behavioral profile of A-4 is OLZ-like, and different from those of A-2 or A-3, although three compounds were synthesized from common leading compounds. A-4, among the three compounds, has been found to most effectively scavenge intracellular ROS formation induced by X-irradiation in human lymphoma U937 cells [15]. In addition, all compounds (A-2, A-3 and A-4) reversed the decrease in GSH concentrations in the $\mathrm{mPFC}$ of neonatal MK-801 treated rats, whereas OLA did not affect them [15]. These findings suggest that the effect of three compounds on MAP-induced hyperactivity in model animals were caused by not only anti-oxidative property, but also antagonistic effects on DA and/or serotonin (5-HT) receptors. Further studies are warranted to confirm the pharmacological profile of apocynin-tandospirone derivatives, especially affinities for $\mathrm{DA}-\mathrm{D}_{2}$ and $5-\mathrm{HT}_{2 \mathrm{~A}}$ receptors.

\subsection{Mechanisms Underlying the Antidopaminergic Effects of Apocynin-Tandospirone Derivatives}

Antidopaminergic effects of apocynin-tandospirone derivatives may be related to phamacologic properties similar to those of the mother compounds. Thus, repeated treatment with apocynin for 7 days dose-dependently decreased MAP-induced locomotor activity and dopamine release in the dorsal striata of rats [28], whereas such effects were absent with acute administration [28]. Therefore, the ability of apocynin to suppress MAPinduced dopamine release and hyperactivity may not totally be due to DA- $\mathrm{D}_{2}$ receptor blockade, but partly to suppression of oxidative stress as a NOX inhibitor [28]. Support for this speculation comes from observations that perinatal transient blockade of NMDA receptors accelerates apoptotic cell death in the hippocampus [41]. Additionally, animals with neonatal excitotoxic lesions of the hippocampus have been shown to elicit increased MAP-induced locomotion after puberty [42,43]. Accordingly, we previously observed that A-2, A-3 and A-4 decrease ROS activities in vitro, and that 14-day treatment with these agents ameliorated disturbances of the GSH system in the animal model used here [15].

Acute treatment with 5- $\mathrm{HT}_{1 \mathrm{~A}}$ agonists, e.g., tandospirone and buspirone, has been shown to increase DA release in the $\mathrm{MPFC}$ and NAC of naïve rats [44-46]. This effect is blocked by systemic administration or local application of WAY 100635, a selective 5-HT $1 \mathrm{~A}$ receptor antagonist [45]. Although tandospirone has a weak antagonistic effect on DA-D 2 receptors $(\mathrm{Ki}: 1.7 \mu \mathrm{M})$ [47], these findings suggested that tandospirone-induced increase in DA levels in the $\mathrm{mPFC}$ is due to stimulation of $5-\mathrm{HT}_{1 \mathrm{~A}}$ receptors [45]. On the other hand, $( \pm$ )-8-hydroxy-2-(di-n-propylamino)-tetralin hydrobromine (8-OH-DPAT), a selective $5-\mathrm{HT}_{1 \mathrm{~A}}$ agonist, inhibited AMPH-induced increases in extracellular DA levels in the mPFC and NAC $[48,49]$. The inhibitory effect of 8-OH-DPAT was completely blocked by WAY 100635. Moreover, 8-OH-DPAT diminished the magnitude of footshock-induced increase in DA utilization in the mPFC [50]. Therefore, $5-\mathrm{HT}_{1 \mathrm{~A}}$ agonism may have differential effects on tonic and phasic DA transmissions in the limbic areas. It is worth noting that SEP-363856, a novel psychotropic agent that lacks $\mathrm{D}_{2}$ receptor affinity, alleviates psychotic symptoms of schizophrenia in a placebo-controlled randomized clinical trial [51]. Importantly, SEP363856 dose-dependently inhibits PCP-induced hyperactivity responses in C57BL/6J mice, which was partially attenuated by pretreatment with WAY-100636 [52]. As PCP increases DA release in the PFC and NAC [53], it is possible that apocynin-tandospirone derivatives suppress increased MAP-induced locomotion and vertical activity through $5-\mathrm{HT}_{1 \mathrm{~A}}$ receptor stimulation. 
Because this study showed the effect of chronic treatment with the novel compounds on MAP-induced hyperactivity in the animal model of schizophrenia, the current data may not directly explain the mechanisms underlining the antidopaminergic effects of apocynintandospirone derivatives. Further studies are warranted to clarify the acute effects of the new drugs on MAP-induced hyperactivity and to confirm the affinity for various receptors of these compounds, especially DA-D2, 5- $\mathrm{HT}_{1 \mathrm{~A}}$ and 5- $\mathrm{HT}_{2 \mathrm{~A}}$ receptors.

\section{Conclusions}

Results of the current study demonstrate that treatment with apocynin-tandospirone derivatives A-2 and A-3 around puberty mitigates increased MAP-induced hyperlocomotion in rats transiently exposed to NMDA blockers in neonatal periods. These findings suggest some of the apocynin-tandospirone derivatives, through antioxidant effects [15], may provide a novel strategy for early intervention and prevention of schizophrenia and related conditions. Specifically, agents to modify redox dysregulation may ameliorate psychotic symptoms and prevent the development of psychosis in vulnerable subjects [3].

Author Contributions: T.U. and M.K. designed the study and wrote the protocol. H.A. synthesized new compounds (A-2 A-4). T.U. and M.K. undertook data collection, in vivo examination and analysis of behavioral data. H.I. undertook data collection in vivo examination. M.K., T.S. and M.S. provided consultation regarding all aspects of the study. T.K., T.S. and M.S. helped with the literature searches. T.U. wrote the first draft of the manuscript. All authors contributed to approval of the final manuscript. All authors have read and agreed to the published version of the manuscript.

Funding: This work was supported by the Japan Society for the Promotion of Science KAKENHI Grant No. 21K07511 to TU and MS, as well as Intramural Research Grants for Neurological and Psychiatric Disorders of NCNP (3-1), Japan Health Research Promotion Bureau Grants (2021-B-01) and KAKENHI Grant No.20H03610 to TS.

Institutional Review Board Statement: The procedures complied with the National Institutes of Health Guide for the Care and Use of Laboratory Animals. All experiments were reviewed and approved by the Committee of Animal Research, University of Toyama.

Informed Consent Statement: Not applicable.

Data Availability Statement: The data that support the findings of this study are available from the corresponding author upon reasonable request.

Acknowledgments: The authors would also be grateful to Yasuhiro Kawasaki for his support.

Conflicts of Interest: The authors declare no conflict of interest.

\section{References}

1. Steullet, P.; Cabungcal, J.H.; Monin, A.; Dwir, D.; O’Donnell, P.; Cuenod, M.; Do, K.Q. Redox dysregulation, neuroinflammation, and NMDA receptor hypofunction: A "central hub" in schizophrenia pathophysiology? Schizophr. Res. 2016, 176, 41-51. [CrossRef] [PubMed]

2. Koga, M.; Serritella, A.V.; Sawa, A.; Sedlak, T.W. Implications for reactive oxygen species in schizophrenia pathogenesis. Schizophr. Res. 2016, 176, 52-71. [CrossRef]

3. Perkins, D.O.; Jeffries, C.D.; Do, K.Q. Potential Roles of Redox Dysregulation in the Development of Schizophrenia. Biol. Psychiatry 2020, 88, 326-336. [CrossRef]

4. Steullet, P.; Cabungcal, J.H.; Coyle, J.; Didriksen, M.; Gill, K.; Grace, A.A.; Hensch, T.K.; LaMantia, A.S.; Lindemann, L.; Maynard, T.M.; et al. Oxidative stress-driven parvalbumin interneuron impairment as a common mechanism in models of schizophrenia. Mol. Psychiatry 2017, 22, 936-943. [CrossRef]

5. Tsugawa, S.; Noda, Y.; Tarumi, R.; Mimura, Y.; Yoshida, K.; Iwata, Y.; Elsalhy, M.; Kuromiya, M.; Kurose, S.; Masuda, F.; et al. Glutathione levels and activities of glutathione metabolism enzymes in patients with schizophrenia: A systematic review and meta-analysis. J. Psychopharmacol. 2019, 33, 1199-1214. [CrossRef]

6. Do, K.Q.; Trabesinger, A.H.; Kirsten-Kruger, M.; Lauer, C.J.; Dydak, U.; Hell, D.; Holsboer, F.; Boesiger, P.; Cuenod, M. Schizophrenia: Glutathione deficit in cerebrospinal fluid and prefrontal cortex in vivo. Eur. J. Neurosci. 2000, 12, 3721-3728. [CrossRef] [PubMed] 
7. Gawryluk, J.W.; Wang, J.F.; Andreazza, A.C.; Shao, L.; Young, L.T. Decreased levels of glutathione, the major brain antioxidant, in post-mortem prefrontal cortex from patients with psychiatric disorders. Int. J. Neuropsychopharmacol. 2011, 14, 123-130. [CrossRef] [PubMed]

8. Mico, J.A.; Rojas-Corrales, M.O.; Gibert-Rahola, J.; Parellada, M.; Moreno, D.; Fraguas, D.; Graell, M.; Gil, J.; Irazusta, J.; CastroFornieles, J.; et al. Reduced antioxidant defense in early onset first-episode psychosis: A case-control study. BMC Psychiatry 2011, 11, 26. [CrossRef]

9. Raffa, M.; Atig, F.; Mhalla, A.; Kerkeni, A.; Mechri, A. Decreased glutathione levels and impaired antioxidant enzyme activities in drug-naive first-episode schizophrenic patients. BMC Psychiatry 2011, 11, 124. [CrossRef]

10. Lavoie, S.; Berger, M.; Schlogelhofer, M.; Schafer, M.R.; Rice, S.; Kim, S.W.; Hesse, J.; McGorry, P.D.; Smesny, S.; Amminger, G.P. Erythrocyte glutathione levels as long-term predictor of transition to psychosis. Transl. Psychiatry 2017, 7, e1064. [CrossRef]

11. Conus, P.; Seidman, L.J.; Fournier, M.; Xin, L.; Cleusix, M.; Baumann, P.S.; Ferrari, C.; Cousins, A.; Alameda, L.; Gholam-Rezaee, M.; et al. N-acetylcysteine in a Double-Blind Randomized Placebo-Controlled Trial: Toward Biomarker-Guided Treatment in Early Psychosis. Schizophr. Bull. 2018, 44, 317-327. [CrossRef]

12. Fone, K.C.; Porkess, M.V. Behavioural and neurochemical effects of post-weaning social isolation in rodents-relevance to developmental neuropsychiatric disorders. Neurosci. Biobehav. Rev. 2008, 32, 1087-1102. [CrossRef]

13. Jones, C.A.; Watson, D.J.; Fone, K.C. Animal models of schizophrenia. Br. J. Pharmacol. 2011, 164, 1162-1194. [CrossRef]

14. Herrmann, A.P.; Benvenutti, R.; Pilz, L.K.; Elisabetsky, E. N-acetylcysteine prevents increased amphetamine sensitivity in social isolation-reared mice. Schizophr. Res. 2014, 155, 109-111. [CrossRef]

15. Uehara, T.; Kurachi, M.; Kondo, T.; Abe, H.; Zhao, Q.L.; Itoh, H.; Sumiyoshi, T.; Suzuki, M. Apocynin-tandospirone derivatives demonstrate antioxidant properties in the animal model of schizophrenia. Adv. Redox Res. 2021, 3, 100013. [CrossRef]

16. Leucht, S.; Corves, C.; Arbter, D.; Engel, R.R.; Li, C.; Davis, J.M. Second-generation versus first-generation antipsychotic drugs for schizophrenia: A meta-analysis. Lancet 2009, 373, 31-41. [CrossRef]

17. Sadowska-Bartosz, I.; Galiniak, S.; Bartosz, G.; Zuberek, M.; Grzelak, A.; Dietrich-Muszalska, A. Antioxidant properties of atypical antipsychotic drugs used in the treatment of schizophrenia. Schizophr. Res. 2016, 176, 245-251. [CrossRef]

18. Brinholi, F.F.; Farias, C.C.; Bonifacio, K.L.; Higachi, L.; Casagrande, R.; Moreira, E.G.; Barbosa, D.S. Clozapine and olanzapine are better antioxidants than haloperidol, quetiapine, risperidone and ziprasidone in in vitro models. Biomed. Pharmacother. 2016, 81 411-415. [CrossRef]

19. Zhao, Q.L.; Ito, H.; Kondo, T.; Uehara, T.; Ikeda, M.; Abe, H.; Saitoh, J.I.; Noguchi, K.; Suzuki, M.; Kurachi, M. Antipsychotic drugs scavenge radiation-induced hydroxyl radicals and intracellular ROS formation, and protect apoptosis in human lymphoma U937 cells. Free Radic. Res. 2019, 53, 304-312. [CrossRef]

20. Uehara, T.; Sumiyoshi, T.; Seo, T.; Itoh, H.; Matsuoka, T.; Suzuki, M.; Kurachi, M. Long-term effects of neonatal MK-801 treatment on prepulse inhibition in young adult rats. Psychopharmacology 2009, 206, 623-630. [CrossRef]

21. Uehara, T.; Sumiyoshi, T.; Seo, T.; Matsuoka, T.; Itoh, H.; Kurachi, M. T-817MA, but Not Haloperidol and Risperidone, Restores Parvalbumin-Positive gamma -Aminobutyric Acid Neurons in the Prefrontal Cortex and Hippocampus of Rats Transiently Exposed to MK-801 at the Neonatal Period. ISRN Psychiatry 2012, 2012, 947149. [CrossRef] [PubMed]

22. Uehara, T.; Sumiyoshi, T.; Seo, T.; Matsuoka, T.; Itoh, H.; Suzuki, M.; Kurachi, M. Neonatal exposure to MK-801, an N-methyl-daspartate receptor antagonist, enhances methamphetamine-induced locomotion and disrupts sensorimotor gating in pre- and postpubertal rats. Brain Res. 2010, 1352, 223-230. [CrossRef]

23. Uehara, T.; Sumiyoshi, T.; Hattori, H.; Itoh, H.; Matsuoka, T.; Iwakami, N.; Suzuki, M.; Kurachi, M. T-817MA, a novel neurotrophic agent, ameliorates loss of GABAergic parvalbumin-positive neurons and sensorimotor gating deficits in rats transiently exposed to MK-801 in the neonatal period. J. Psychiatr. Res. 2012, 46, 622-629. [CrossRef] [PubMed]

24. Uehara, T.; Sumiyoshi, T.; Matsuoka, T.; Itoh, H.; Kurachi, M. Effect of prefrontal cortex inactivation on behavioral and neurochemical abnormalities in rats with excitotoxic lesions of the entorhinal cortex. Synapse 2007, 61, 391-400. [CrossRef] [PubMed]

25. Boctor, S.Y.; Ferguson, S.A. Altered adult locomotor activity in rats from phencyclidine treatment on postnatal days 7, 9 and 11, but not repeated ketamine treatment on postnatal day 7. Neurotoxicology 2010, 31, 42-54. [CrossRef]

26. Kocahan, S.; Akillioglu, K.; Binokay, S.; Sencar, L.; Polat, S. The effects of N-Methyl-D-Aspartate receptor blockade during the early neurodevelopmental period on emotional behaviors and cognitive functions of adolescent Wistar rats. Neurochem. Res. 2013, 38, 989-996. [CrossRef]

27. Robinson, T.E.; Becker, J.B. Enduring changes in brain and behavior produced by chronic amphetamine administration: A review and evaluation of animal models of amphetamine psychosis. Brain Res. 1986, 396, 157-198. [CrossRef]

28. Miller, D.K.; Oelrichs, C.E.; Sun, G.Y.; Simonyi, A. Subchronic apocynin treatment attenuates methamphetamine-induced dopamine release and hyperactivity in rats. Life Sci. 2014, 98, 6-11. [CrossRef]

29. Weinberger, D.R. Neurodevelopmental perspectives on schizophrenia. In Psychopharmacology; The Forth Generation of Progress; Bloom, F.E., Kupfer, D.J., Eds.; Raven Press: New York, NY, USA, 1995; pp. 1171-1183.

30. Fink, J.S.; Smith, G.P. Mesolimbic and mesocortical dopaminergic neurons are necessary for normal exploratory behavior in rats. Neurosci. Lett. 1980, 17, 61-65. [CrossRef]

31. Thiel, C.M.; Muller, C.P.; Huston, J.P.; Schwarting, R.K. High versus low reactivity to a novel environment: Behavioural, pharmacological and neurochemical assessments. Neuroscience 1999, 93, 243-251. [CrossRef] 
32. Bubenikova-Valesova, V.; Kacer, P.; Syslova, K.; Rambousek, L.; Janovsky, M.; Schutova, B.; Hruba, L.; Slamberova, R. Prenatal methamphetamine exposure affects the mesolimbic dopaminergic system and behavior in adult offspring. Int. J. Dev. Neurosci. 2009, 27, 525-530. [CrossRef] [PubMed]

33. Groos, D.; Zheng, F.; Rauh, M.; Quinger, B.; Kornhuber, J.; Muller, C.P.; Alzheimer, C. Chronic antipsychotic treatment targets GIRK current suppression, loss of long-term synaptic depression and behavioural sensitization in a mouse model of amphetamine psychosis. J. Psychopharmacol. 2019, 33, 74-85. [CrossRef] [PubMed]

34. Sun, T.; Hu, G.; Li, M. Repeated antipsychotic treatment progressively potentiates inhibition on phencyclidine-induced hyperlocomotion, but attenuates inhibition on amphetamine-induced hyperlocomotion: Relevance to animal models of antipsychotic drugs. Eur. J. Pharmacol. 2009, 602, 334-342. [CrossRef] [PubMed]

35. Abekawa, T.; Ito, K.; Koyama, T. Different effects of a single and repeated administration of clozapine on phencyclidine-induced hyperlocomotion and glutamate releases in the rat medial prefrontal cortex at short- and long-term withdrawal from this antipsychotic. Naunyn-Schmiedeberg's Arch. Pharmacol. 2007, 375, 261-271. [CrossRef] [PubMed]

36. Herrera, A.S.; Casanova, J.P.; Gatica, R.I.; Escobar, F.; Fuentealba, J.A. Clozapine pre-treatment has a protracted hypolocomotor effect on the induction and expression of amphetamine sensitization. Prog. Neuropsychopharmacol. Biol. Psychiatry 2013, 47, 1-6. [CrossRef] [PubMed]

37. Tung, C.S.; Chang, S.T.; Huang, C.L.; Huang, N.K. The neurotoxic mechanisms of amphetamine: Step by step for striatal dopamine depletion. Neurosci. Lett. 2017, 639, 185-191. [CrossRef]

38. Basmadjian, O.M.; Occhieppo, V.B.; Marchese, N.A.; Silvero, C.M.; Becerra, M.C.; Baiardi, G.; Bregonzio, C. Amphetamine Induces Oxidative Stress, Glial Activation and Transient Angiogenesis in Prefrontal Cortex via AT1-R. Front. Pharmacol. 2021, 12, 647747. [CrossRef]

39. Yamamoto, B.K.; Raudensky, J. The role of oxidative stress, metabolic compromise, and inflammation in neuronal injury produced by amphetamine-related drugs of abuse. J. Neuroimmune Pharmacol. 2008, 3, 203-217. [CrossRef]

40. Todorovic, N.; Filipovic, D. Prefrontal cortical glutathione-dependent defense and proinflammatory mediators in chronically isolated rats: Modulation by fluoxetine or clozapine. Neuroscience 2017, 355, 49-60. [CrossRef]

41. Ikonomidou, C.; Bosch, F.; Miksa, M.; Bittigau, P.; Vockler, J.; Dikranian, K.; Tenkova, T.I.; Stefovska, V.; Turski, L.; Olney, J.W. Blockade of NMDA receptors and apoptotic neurodegeneration in the developing brain. Science 1999, 283, 70-74. [CrossRef]

42. Lipska, B.K.; Jaskiw, G.E.; Weinberger, D.R. Postpubertal emergence of hyperresponsiveness to stress and to amphetamine after neonatal excitotoxic hippocampal damage: A potential animal model of schizophrenia. Neuropsychopharmacology 1993, 9, 67-75. [CrossRef] [PubMed]

43. Lipska, B.K.; Swerdlow, N.R.; Geyer, M.A.; Jaskiw, G.E.; Braff, D.L.; Weinberger, D.R. Neontal excitotoxic hippocampal damage in rats causes post-pubertal changes in prepulse inhibition of startle and its disruption by apomorphine. Psychopharmacology $\mathbf{1 9 9 5}$ 122, 35-43. [CrossRef]

44. Gobert, A.; Rivet, J.M.; Cistarelli, J.M.; Millan, M.J. Buspirone enhances duloxetine- and fluoxetine-induced increases in dialysate levels of dopamine and noradrenaline, but not serotonin, in the frontal cortex of freely moving rats. J. Neurochem. 1997, 68, 1326-1329. [CrossRef] [PubMed]

45. Yoshino, T.; Nisijima, K.; Katoh, S.; Yui, K.; Nakamura, M. Tandospirone potentiates the fluoxetine-induced increases in extracellular dopamine via 5-HT(1A) receptors in the rat medial frontal cortex. Neurochem. Int. 2002, 40, 355-360. [CrossRef]

46. Huang, M.; Panos, J.J.; Kwon, S.; Oyamada, Y.; Rajagopal, L.; Meltzer, H.Y. Comparative effect of lurasidone and blonanserin on cortical glutamate, dopamine, and acetylcholine efflux: Role of relative serotonin (5-HT)2A and DA D2 antagonism and 5-HT1A partial agonism. J. Neurochem. 2014, 128, 938-949. [CrossRef]

47. Hamik, A.; Oksenberg, D.; Fischette, C.; Peroutka, S.J. Analysis of tandospirone (SM-3997) interactions with neurotransmitter receptor binding sites. Biol. Psychiatry 1990, 28, 99-109. [CrossRef]

48. Kuroki, T.; Ichikawa, J.; Dai, J.; Meltzer, H.Y. R(+)-8-OH-DPAT, a 5-HT1A receptor agonist, inhibits amphetamine-induced serotonin and dopamine release in rat medial prefrontal cortex. Brain Res. 1996, 743, 357-361. [CrossRef]

49. Ichikawa, J.; Kuroki, T.; Kitchen, M.T.; Meltzer, H.Y. R(+)-8-OH-DPAT, a 5-HT1A receptor agonist, inhibits amphetamine-induced dopamine release in rat striatum and nucleus accumbens. Eur. J. Pharmacol. 1995, 287, 179-184. [CrossRef]

50. Rasmusson, A.M.; Goldstein, L.E.; Deutch, A.Y.; Bunney, B.S.; Roth, R.H. 5-HT1a agonist +/-8-OH-DPAT modulates basal and stress-induced changes in medial prefrontal cortical dopamine. Synapse 1994, 18, 218-224. [CrossRef]

51. Koblan, K.S.; Kent, J.; Hopkins, S.C.; Krystal, J.H.; Cheng, H.; Goldman, R.; Loebel, A. A Non-D2-Receptor-Binding Drug for the Treatment of Schizophrenia. N. Engl. J. Med. 2020, 382, 1497-1506. [CrossRef]

52. Dedic, N.; Jones, P.G.; Hopkins, S.C.; Lew, R.; Shao, L.; Campbell, J.E.; Spear, K.L.; Large, T.H.; Campbell, U.C.; Hanania, T.; et al. SEP-363856, a Novel Psychotropic Agent with a Unique, Non-D2 Receptor Mechanism of Action. J. Pharmacol. Exp. Ther. 2019, 371, 1-14. [CrossRef] [PubMed]

53. Zuo, D.; Bzdega, T.; Olszewski, R.T.; Moffett, J.R.; Neale, J.H. Effects of N-acetylaspartylglutamate (NAAG) peptidase inhibition on release of glutamate and dopamine in prefrontal cortex and nucleus accumbens in phencyclidine model of schizophrenia. $J$. Biol. Chem. 2012, 287, 21773-21782. [CrossRef] [PubMed] 